\title{
MOVEMENT OF FORAGING TUNDRA SWANS EXPLAINED BY SPATIAL PATTERN IN CRYPTIC FOOD DENSITIES
}

\author{
Raymond H. G. KlaAssen, ${ }^{1,3}$ Bart A. Nolet, ${ }^{1}$ and Daniëlle Bankert ${ }^{1,2}$ \\ ${ }^{1}$ Department of Plant-Animal Interactions, Netherlands Institute of Ecology (NIOO-KNAW), Rijksstraatweg 6, \\ 3631AC Nieuwersluis, The Netherlands \\ ${ }^{2}$ Resource Ecology Group, Wageningen University, P.O. Box 9101, 6700 HB Wageningen, The Netherlands
}

\begin{abstract}
We tested whether Tundra Swans use information on the spatial distribution of cryptic food items (belowground Sago pondweed tubers) to shape their movement paths. In a continuous environment, swans create their own food patches by digging craters, which they exploit in several feeding bouts. Series of short $(<1 \mathrm{~m})$ intra-patch movements alternate with longer inter-patch movements $(>1 \mathrm{~m})$. Tuber biomass densities showed a positive spatial autocorrelation at a short distance $(<3 \mathrm{~m})$, but not at a larger distance $(3-8 \mathrm{~m})$. Based on the spatial pattern of the food distribution (which is assumed to be pre-harvest information for the swan) and the energy costs and benefits for different food densities at various distances, we calculated the optimal length of an inter-patch movement. A swan that moves to the patch with the highest gain rate was predicted to move to the adjacent patch (at $1 \mathrm{~m}$ ) if the food density in the current patch had been high $\left(>25 \mathrm{~g} / \mathrm{m}^{2}\right)$ and to a more distant patch (at 7-8 $\mathrm{m}$ ) if the food density in the current patch had been low $\left(<25 \mathrm{~g} / \mathrm{m}^{2}\right)$. This prediction was tested by measuring the response of swans to manipulated tuber densities. In accordance with our predictions, swans moved a long distance $(>3 \mathrm{~m})$ from a low-density patch and a short distance $(<3 \mathrm{~m})$ from a high-density patch. The quantitative agreement between prediction and observation was greater for swans feeding in pairs than for solitary swans. The result of this movement strategy is that swans visit high-density patches at a higher frequency than on offer and, consequently, achieve a $38 \%$ higher long-term gain rate. Swans also take advantage of spatial variance in food abundance by regulating the time in patches, staying longer and consuming more food from rich than from poor patches. We can conclude that the shape of the foraging path is a reflection of the spatial pattern in the distribution of tuber densities and can be understood from an optimal foraging perspective.
\end{abstract}

Key words: animal movement; area-restricted search; Cygnus columbianus bewickii; inter-patch distance; optimal foraging; Potamogeton pectinatus; spatial heterogeneity; step length; Tundra Swan; turning angle.

\section{INTRODUCTION}

Heterogeneity in the abundance of food items is a widespread phenomenon in natural ecosystems (Sparrow 1999). Spatial variance ( $\mathrm{Li}$ and Reynolds 1995) in food density has a direct effect on the instantaneous intake rate of a forager, as depicted by the functional response (Holling 1959). Optimal foraging theory predicts that foragers adjust the time in a patch ("patch residence time") to the food density in order to maximize their long-term energy gain rate (Charnov 1976, Stephens and Krebs 1986). A less acknowledged aspect of a heterogeneous food distribution is spatial pattern (Li and Reynolds 1995). For example, a positive spatial autocorrelation will result in high-density patches found close to other high-density patches and low-density patches found close to other low-density patches (Legendre 1993). In a large range of food distributions,

Manuscript received 7 November 2005; revised 21 February 2006; accepted 2 March 2006. Corresponding Editor: B. P. Kotler.

${ }^{3}$ E-mail: r.klaassen@nioo.knaw.nl it is beneficial to a forager to respond to spatial pattern by regulating the shape of the foraging path, since this results in more visits to high-density patches and, consequently, a higher energy gain rate (Benhamou 1992). It is commonly observed that animals intensify search by regulating movement after a prey encounter, a phenomenon called area-restricted search or area-concentrated search (Bovet and Benhamou 1988, Walsh 1996). When a forager is omniscient about the quality and position of patches, movement becomes a "traveling salesman problem": What is the shortest path that visits (high-density) patches (Anderson 1983)? When a forager is not omniscient, for example, because prey are cryptic, the optimal movement rule is more complex. However, a forager can estimate the quality of nearby patches by combining current-patch sample information with preharvest information about the spatial pattern of the food distribution (Mangel and Adler 1994, Valone 1991), and might try to move to the patch where the highest gain rate is expected. This idea is especially valid for nondiscrete environments, where patches cannot be recognized beforehand, but are defined by the behavior of the 

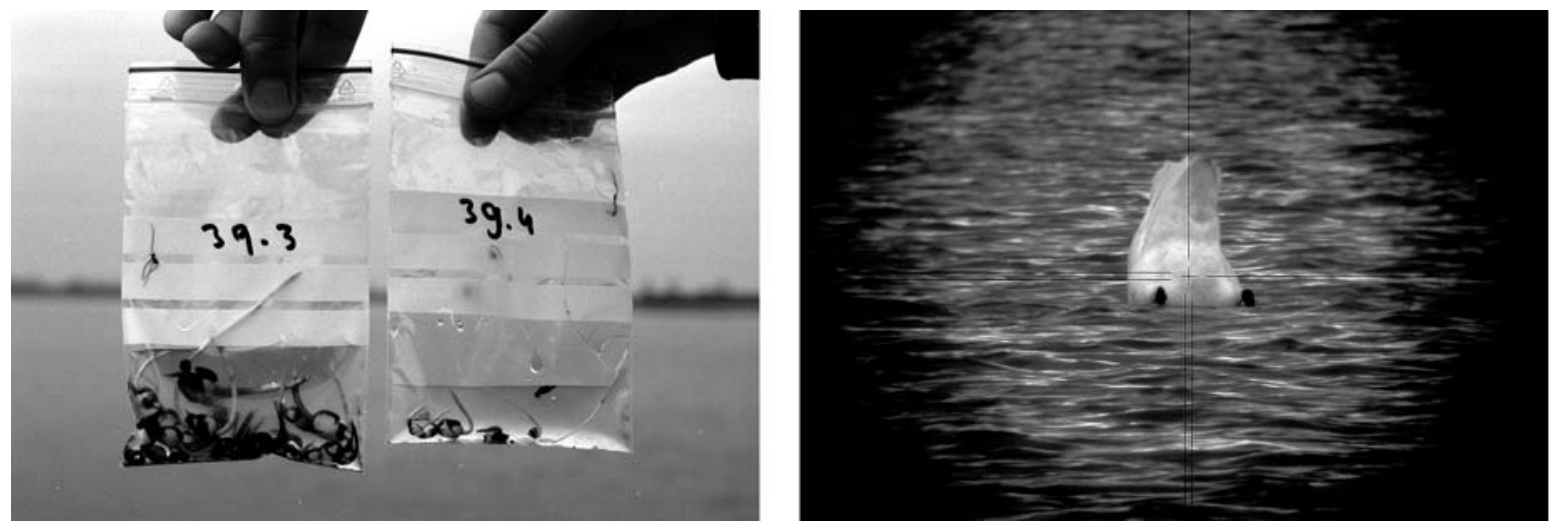

Plate 1. (Left) Freshly collected Sago pondweed (Potamogeton pectinatus) tubers from two subplots. This picture nicely illustrates that tuber biomass densities vary enormously throughout this otherwise relatively homogeneous environment. (Right) View through a total station range finder while recording the exact position of an up-ending Tundra Swan (Cygnus columbianus bewickii) feeding on Sago pondweed tubers. In order to make an accurate triangular fix of the position of the swan the range finder's crosshairs had to be pointed at the middle of the target swan. Photo credit: R. H. G. Klaassen

forager (patches are invented by the forager; cf. Kacelnik and Bernstein 1988).

A foraging path can be represented as a series of movements with a certain length and turning angle between subsequent movements (Turchin 1998). Usually paths exhibit nonrandom features, like a skewed distribution of movement lengths or a strong sinuosity, which are thought to be related to the distribution of food items. The movement pattern of animals in relation to the spatial distribution of food has been studied intensively by simulating movement patterns by biased random walks and correlated random walks (e.g., Kareiva and Shigesada 1983, Bovet and Benhamou 1988, Focardi et al. 1996, Nolet and Mooij 2002, Fortin 2003, Morales et al. 2004). The simulated movement patterns can describe observed movement patterns well, but these models lack an important feature, since individual movements are not related to the food distribution. Consequently, this approach does not help us to understand what factors shape a foraging path, or, in other words, why a movement has a certain length or turning angle. In order to fully understand the shape of a path, we should relate the length and the angle of turn of individual movements to the distribution of food items.

Here we studied movements of the Tundra Swan, Cygnus columbianus bewickii, in relation to the smallscale spatial pattern in distribution of food densities (tubers of Sago pondweed, Potamogeton pectinatus) (see Plate 1). Earlier studies in this system focused on intake rates during pondweed feeding (Nolet et al. 2001), energetic costs of foraging (Nolet et al. 2002), and largescale movements during pondweed foraging (Nolet and Mooij 2002). In this study, we determined the spatial pattern in the distribution of food and subsequently established quantitative predictions about the optimal lengths of inter-patch movements for this spatial pattern. These predictions were tested in the field by measuring lengths of inter-patch movements in subplots where the abundance of food was manipulated experimentally.

\section{Methods \\ Study system}

Lauwersmeer is a shallow freshwater lake situated in northern Netherlands $\left(53^{\circ} 22^{\prime} \mathrm{N}, 06^{\circ} 13^{\prime} \mathrm{E}\right)$. In Lauwersmeer, Sago pondweed occurs in large and dense stands, and survives the winter as tubers that are buried within the top $30 \mathrm{~cm}$ of the sediment (Santamaría and Rodríguez-Gironés 2002). In late autumn, the Lauwersmeer serves as a last stopover site for the migratory Tundra Swans before they arrive at their wintering grounds. Swans almost exclusively forage on pondweed tubers during a relatively short period of about three weeks, before they leave the area or switch to harvest leftovers on nearby farmlands (Beekman et al. 1991, Nolet et al. 2002). Tuber stocks are not renewed during this period, but are heavily depleted (biomass reduction of 25-80\%; B. A. Nolet, unpublished data). A flock of swans moves systematically through a pondweed bed (Beekman et al. 1991, Van Eerden et al. 1997), and, consequently, swans encounter an unexploited part of the pondweed bed every time the flock progresses.

Swans loosen the sediment by trampling with their legs, which creates craters, and subsequently retrieve tubers by sieving the loosened sediment with their heads submerged. A foraging bout consists of a sequence of trampling, feeding, and surfacing. A crater is depleted in a series of foraging bouts. The size of a crater is $\sim 1 \mathrm{~m}^{2}$ (Van Eerden et al. 1997; R. H. G. Klaassen, personal observation).

We assume that tubers are cryptic to swans, since they are buried in the sediment and aboveground parts and belowground rhizomes have died off and disappeared at the time of swan exploitation. Swans have access to different sources of information about the density of 

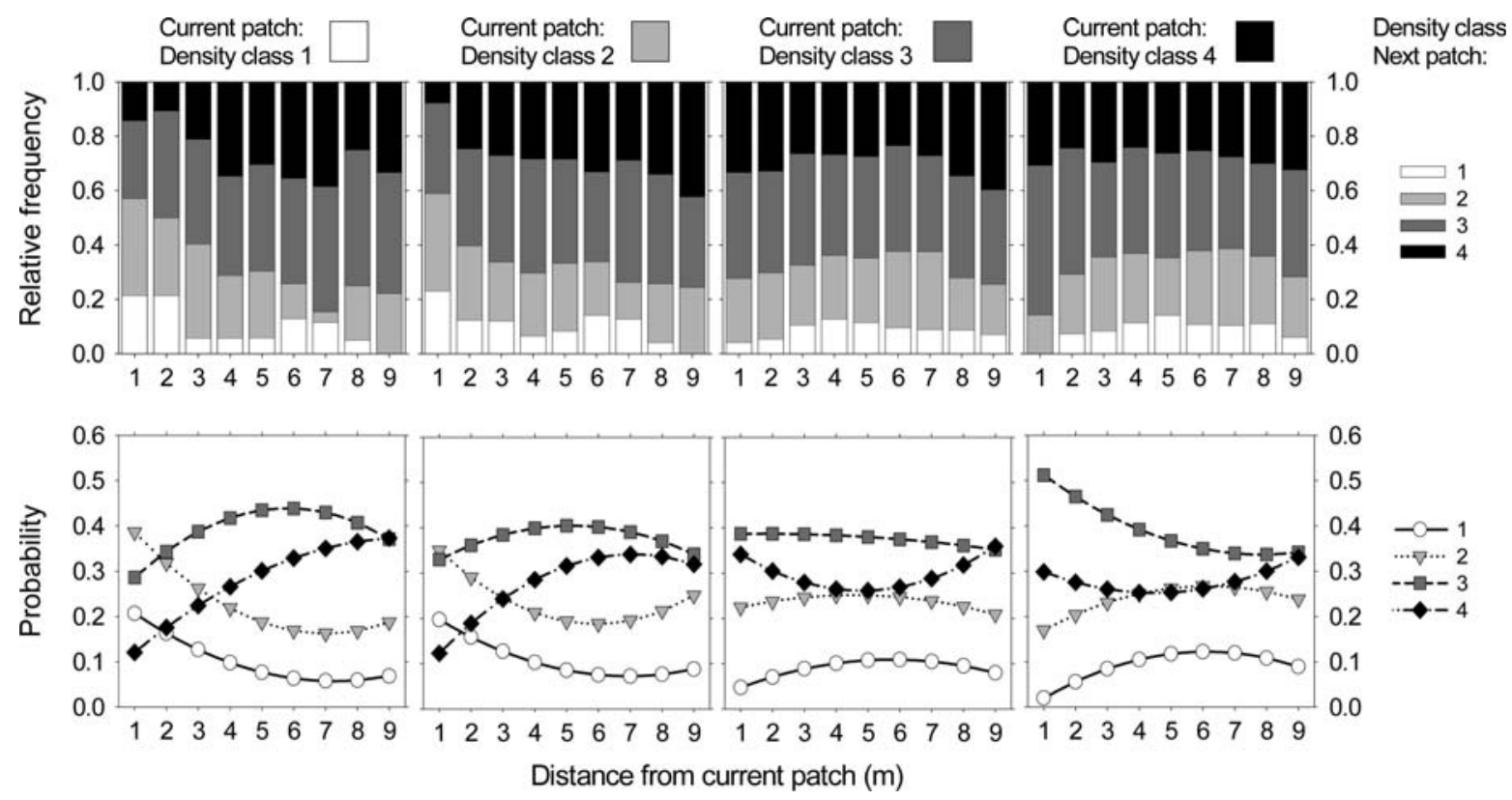

FIG. 1. A description of spatial pattern in the distribution of food densities from the perspective of the forager. The upper panels illustrate the frequencies in which different density classes $D$ are found ( $y$-axis) in squares (patches from the forager's perspective) at distance $i$ from the current square ( $x$-axis), given the density class of the current square (different panels). Densities were categorized into four classes (class $1,<15 \mathrm{~g} / \mathrm{m}^{2}$; class $2,15-25 \mathrm{~g} / \mathrm{m}^{2}$; class $3,25-35 \mathrm{~g} / \mathrm{m}^{2}$; and class $4,>35 \mathrm{~g} / \mathrm{m}^{2}$ ). The lower panels provide the probability that a square of a certain food density class is encountered at different distances from the current square, for different food densities in the current square. These functions are called "structure functions," and are second-order polynomials fitted to observed frequencies (upper panels).

food. We distinguished between patch sample information (food density and time in current patch), preharvest information (distribution of food densities), and public information (knowledge shared by individuals foraging in a flock) (Valone 1991). Pre-harvest information can further be divided into the frequency and spatial distribution of food densities.

\section{Food distribution}

In early October, prior to the arrival of swans, we sampled the tuber densities by taking 40-cm deep cores (diameter $10 \mathrm{~cm}$ ) and filtering the sediment through a 3$\mathrm{mm}$ sieve. Tubers were dried at $70^{\circ} \mathrm{C}$ for $72 \mathrm{~h}$ before weighed to the nearest $0.001 \mathrm{~g}$. Biomass densities are given in dry mass per area.

Small-scale spatial heterogeneity.-In order to determine the spatial pattern in the distribution of tuber densities, we sampled tuber densities in a $10 \times 10$ grid of (adjacent) $1-\mathrm{m}^{2}$ squares by taking 12 cores per square (see Appendix B: Fig. B1). Densities were deliberately measured at this detailed scale (i.e., per $1 \mathrm{~m}^{2}$ ), since this is equal to the foraging scale of swans. The fact that sampling is an extremely laborious procedure precluded sampling of a larger area at this minute scale (it took six people three days to sample the grid). We assumed that the spatial pattern observed in this grid was representative for a sandy-shallow site.

As a measure of spatial autocorrelation in tuber biomass density, Moran's I was calculated under the randomization hypothesis using the Rookcase add-in, with adjacency defined as Queen's (Sawada 1999). In addition, spatial pattern was described by structure functions, which give the probability that a point some distance $i$ away from a given point is in a certain resource state, conditioned on the resource state in the current point (Mangel and Adler 1994). Tuber biomass densities were categorized in four classes $D$ (class $1,<15$ $\mathrm{g} / \mathrm{m}^{2}$; class 2, 15-25 g/m $\mathrm{m}^{2}$; class $3,25-35 \mathrm{~g} / \mathrm{m}^{2}$; and class $4,>35 \mathrm{~g} / \mathrm{m}^{2}$ ). We subsequently determined the frequency in which different density classes occurred at different distances $i$ from focal squares of the same food density class. For example, the upper left panel in Fig. 1 shows the frequencies in which different density classes were encountered at distances $i$ from focal squares with food density class 1 . Second-order polynomials were fitted to these observed frequencies (lower panels in Fig. 1) to form the structure functions, i.e., the probability that a square (or patch from the swans' perspective) with density $a$ is found at a distance $i$ from a current patch with density $b$. The average $R^{2}$ of fits of modeled structure functions equaled 0.64 .

Food manipulation.-We manipulated pondweed densities in a plot consisting of $10 \times 10 \mathrm{~m}$ subplots, aligned in a $4 \times 8$ array, by removing aboveground biomass at different stages during the growing season (treatment: June, July, or August, or not removed [control]), according to a random-block design (8 subplots per treatment; see Appendix B: Fig. B1). Aboveground 
biomass was removed by dragging a $54-\mathrm{cm}$ broad knifeblade through the subplot. In October, we took 24 cores per subplot to determine average tuber densities. Water depth and sediment type did not differ substantially between subplots. Subplots were located near transects 12 and 13 from Nolet et al. (2001) and can be characterized as sandy-shallow (see Nolet et al. 2001 for details).

\section{Measuring foraging paths}

In order to determine the responses of foraging swans to different tuber densities, we measured their behavior and movement paths in the subplots where food densities had been manipulated. The range of food densities observed in the subplots was comparable to the range of densities observed in the grid. We assumed that the food density a swan observed in a patch located in a given subplot was equal to the average food density in that subplot. The actual density that a swan encountered might be slightly different because of small-scale heterogeneity. However, we believe that this effect was negligible since the removal of aboveground biomass was expected to substantially homogenize biomass abundance within subplots. The spatial pattern in the manipulated plot was not equal to the spatial pattern in the unmanipulated part of the pondweed bed. As the manipulated plot was only $1.5 \%$ of the pondweed bed as a whole, we assumed that swans did not learn the experimentally induced pattern in the distribution of tuber densities, but that they moved in response to encountered tuber densities as if they were in an unmanipulated environment.

Foraging Tundra Swans were observed from two blinds located on the shore adjacent to the pondweed bed (blinds stood $40 \mathrm{~m}$ apart; minimum and maximum distance to a swan in a plot was $44 \mathrm{~m}$ and $120 \mathrm{~m}$, respectively). About 250 swans visited the study area. A focal swan was selected haphazardly from swans foraging in or close to experimental plots. We could not recognize individual swans, so we could not fully prevent observations on the same individuals. However, we have a strong impression that the vast majority of observations were made on different birds. We mapped the foraging path of a focal swan by taking a triangular fix of the position of the swan every time it submerged its head by simultaneously measuring the angle to the swan from the two blinds using two total station range finders (TCR307, Leica Geosystems AG, St. Gallen, Switzerland; see Plate 1). Angles were measured with great accuracy (divergence maximal of $7^{\prime \prime}$ or 2 mgon [360 degrees $=400$ gon], which equals an error of $3.8 \mathrm{~mm}$ at $120 \mathrm{~m}$ ). The inaccuracy of a measurement was mainly the result of a difference in the exact placement of the cross hairs of the range finders on the target swan. This difference would result in a divergence from the actual position of maximally $0.23-0.67 \mathrm{~m}$ for a measurement of a swan at $44-120 \mathrm{~m}$ from the blinds, respectively (if we assume that both rangefinders were aimed at a spot 10 $\mathrm{cm}$ from the middle of the swan, which equals one-third of the body width of an up-ending swan). In addition, we continuously recorded the behavior of the swan on audiotape. Afterwards, the timing, duration, and type of all behavior were determined to the nearest $0.1 \mathrm{~s}$ using the Observer software (Noldus Information Technology, Wageningen, The Netherlands).

For each focal swan, the social status (single, pair, or family) was recorded. Furthermore, we recorded all disturbances, especially interactions with other swans. A focal swan was followed for 30 minutes, or until it was out of sight of a total station (a swan foraging in the plot was never out of sight). Measurements were conducted from 16-31 October 2003, which covered the complete period of swan exploitation of the pondweed bed. Observations were conducted from dawn to dusk.

\section{Defining patches and movements}

A pondweed bed is a clear example of a non-discrete environment where foraging patches cannot be recognized a priori. In this system, we defined a patch as the crater dug by a trampling swan and exploited in several foraging bouts (see Methods: Study system). A movement of a swan was defined as the distance between two fixes (positions where the swan submerged its head). Since a patch is exploited in several bouts, a series of (relatively small) intra-patch movements alternate with (relatively large) inter-patch movements. It was not straightforward to distinguish intra- and inter-patch movements by their length, since an inter-patch movement can sometimes be smaller than an intra-patch movement (i.e., there is overlap in the frequency distribution of intra- and inter-patch movement lengths, see Results); for example, if a new patch was initiated adjacent to the previous patch. Consequently, we distinguished intra- and inter-patch movements based on the spatial separation of series of fixes. This method was founded on the observation that the first half of fixes in a patch typically had an overlap of $>80 \%$ with the second half of fixes. We defined that a swan exploited two adjacent patches rather than one larger patch if the series of fixes showed $<5 \%$ overlap (one out of 20 fixes was allowed to coincide with the previous series of fixes). By using this definition, we could even distinguish between adjacent patches, i.e., no distance between craters, which was in accordance with observations in the field (R. H. G. Klaassen, personal observation). Intra- and inter-patch movements were recognized after all individual fixes were assigned to different patches. The position of a patch was the average of the fixes in that patch.

\section{Calculations and statistics}

For every inter-patch movement, we determined whether it was "free" or related to a social interaction. In this analysis we only considered free movements because we were only interested in the response of the swan to spatial pattern $(76 \%$ of all movements in this 
study). For each patch, we determined the patch residence time and the length and turning angle of intra- and interpatch movements. These were linked to the food density at the patch location (i.e., the average density in the subplot in which the patch was located, as measured prior to swan arrival), categorized into four density classes $D$. The effect of aboveground biomass treatment on tuber density in October was analyzed by a one-way ANOVA. The effect of food density class and social status on patch residence time, duration of one foraging bout, number of bouts per patch, and length of an inter-patch movement was analyzed by two-way ANOVAs. Analyses were conducted using the STATISTICA software (version 6.1; StatSoft 2004). The effect of tuber density class on turning angle was analyzed by the nonparametric Mardia-Watson-Wheeler test (Batschelet 1981).

A swan that moves systematically or randomly through the environment encounters food density classes in the same frequency as they are on offer. We compared the frequencies that density classes were on offer in our subplots to the frequencies with which the swans encountered different classes in our subplots by calculating the Ivlev-index $I$ (Krebs 1989) for every density class $D$ :

$$
I_{D}=\left(f_{u, D}-f_{o, D}\right) /\left(f_{u, D}+f_{o, D}\right)
$$

in which $f_{u}$ is the frequency of density class $D$ encountered by the swans, and $f_{o}$ is the frequency of density class $D$ on offer in our subplots.

\section{Model Predictions \\ Expected gain rate}

First, for every density class $D$, we calculated the gross amount of biomass $g_{D}$ (in grams) that a swan consumed from a patch, given the swan's functional response and the observed time foraging for that density class (cf. Kotler and Brown 1990). The initial food density was equal to the midrange density for that class. The expected gross energy gain $\hat{g}_{D}$ (in joules) for density class $D$ is subsequently calculated by multiplying $g_{D}$ with the energy density of tubers (joules per gram) and the assimilation efficiency. Second, for every density class $D$, we calculated the expected energetic costs $\hat{c}_{D, i}$ (in joules) for a patch. This includes the cost to move to that patch, and since this is a function of distance $i$, the expected energetic costs is also a function of distance $i$ (in meters): $\hat{c}_{D, i}=t_{\text {surf }} \times e_{\text {surf }}+t_{\text {tram }} \times e_{\text {tram }}+t_{\text {feed }} \times e_{\text {feed }}+t_{\text {mov }} \times e_{\text {mov }}$

in which $t$ is the observed duration (in seconds) and $e$ the energy expenditure (joules per second) of a behavior (subscript abbreviations are: surf, surfacing; feed, feeding; tram, trampling; and mov, moving). The time moving is a function of distance $i: t_{\mathrm{mov}}=i \times\left(V_{\mathrm{mov}}\right)^{-1}$, in which $V_{\text {mov }}$ is the velocity of movement (meters per second). Third, for every density class $D$, we calculated the expected time $\hat{t}_{D, i}$ (in seconds) related to a patch, which includes the time to move to that patch, by summing the observed durations of the different behaviors. Finally, we calculated the expected net energy gain rate $\hat{n}_{D, i}$ (in joules per second) for every density class $D$ for a patch at distance $i$ from the current patch:

$$
\hat{n}_{D, i}=\frac{\hat{g}_{D}-\hat{c}_{D, i}}{\hat{t}_{D, i}} .
$$

Parameter values in these calculations were estimated in this study or derived from Nolet et al. (2002) (see Appendix A: Table A1).

The net gain rate that a swan expects in a patch at distance $i$ from the current patch $c$, given the density in the current patch, can be predicted from the expected gain rates $\hat{n}_{D, i}$ for the different density classes $D$ and the probabilities that these density classes are encountered, according to

$$
\hat{n}_{i} \mid\left(D_{c}=b\right)=\sum_{a=1}^{4} \hat{n}_{D=a, i} \times P\left(D_{i}=a \mid D_{c}=b\right) .
$$

Here, $b$ is the density class of the current patch, and $a$ is the density class of the patch at distance i. $P\left(D_{i}=a \mid D_{c}=\right.$ $b$ ) is equal to the structure function (see Fig. 1). In Fig. $2 \mathrm{a}$, we illustrate how the expected net gain rate $\hat{n}$ varies over distance $i$ for different food densities in the current patch.

\section{Length of inter-patch movements}

We predicted that a swan always moves to the patch where the highest gain rate is expected. As a result of the positive spatial autocorrelation in the distribution of food densities (see Results), the highest gain rate is expected in a nearby patch if the food density in the current patch is high, and in a more distant patch if the food density in the current patch is low (Fig. 2). Consequently, we predicted that a swan makes a large movement from a patch that was poor in food (predicted length of a movement is $7 \mathrm{~m}$ and $8 \mathrm{~m}$ from a patch with a food density class 1 and 2, respectively) and a small movement from a patch that was rich in food (predicted length of a movement was $1 \mathrm{~m}$ from a patch with food density classes 3 and 4) (Fig. 2b). We assumed that the decision on the length of an inter-patch movement is based on the density in the current patch only ("instantaneous decision"), rather than based on a number of patches.

\section{Long-term gain rate}

The long-term gain rate $G$ that a swan achieves depends on the frequency in which different density classes are encountered $f(D)$. A swan that always moves to the patch where the highest gain rate is expected encounters highdensity patches at a higher frequency than they are on offer and low-density patches at a lower frequency. The long-term gain rate is calculated according to

$$
G=\sum_{b=1}^{4}(\hat{n} \mid D=b) \times f(D=b)
$$

in which $\hat{n} \mid D=b$ is the (maximum) gain rate related to 
the movement from a patch with density $D=b$ (for example, for density class 1 this would equal $\hat{n}_{i=7}$ ). A swan that is not sensitive to spatial pattern moves randomly throughout the environment and consequently encounters food densities in the same frequency as they are on offer. For simplicity, we assumed here that such a forager always moves to the adjacent patch $(i$ $=1)$ to minimize movement costs. The long-term gain rate is calculated according to the same formula in which $\hat{n} \mid D=b$ now is equal to $\hat{n}_{i=1} \mid D$ (for example, $\hat{n}_{i=1}$ for density class 1 ).

\section{RESUlts}

\section{Spatial pattern in food distribution}

Tuber densities varied considerably within the grid $\left(30.8 \pm 12.6 \mathrm{~g} / \mathrm{m}^{2}\right.$ [mean $\pm \mathrm{sD}$ ], range $9.0-85.9 \mathrm{~g} / \mathrm{m}^{2}$; see Plate 1 and Appendix B: Fig. B2). Densities were not randomly distributed, but rather showed a highly significant positive autocorrelation in tuber biomass densities (Moran's $I=0.160, P=0.0002$ ). The frequency in which different densities were encountered was different for different distances from the current patch, and depended on the food density in the current patch (Fig. 1). The frequency of low-density patches (class 1 and 2) was highest close to a low-density patch, and decreased with an increasing distance. Similarly, the frequency of high-density patches (class 3 and 4) was highest close to a high-density patch, decreased with an increasing distance. However, at a relatively long distance $(>8 \mathrm{~m})$ from a low- or a high-density patch, the frequency of respectively low- and high-density patches increased again (Fig. 1).

\section{Foraging paths of Tundra Swans}

We measured the foraging path of 137 individual swans, from which the social status could be determined in 124 cases. Three representative examples of a part of the foraging path are provided in Fig. 3. The frequency distribution of the lengths of all recorded movements (no distinction between intra- and inter-patch movements) was bimodal (Fig. 4a). The fit of a mixture of two normal distributions with a probability density of $q \cdot \mathcal{N}\left(\mu_{1}, \sigma_{1}\right)+(1-q) \cdot \mathcal{N}\left(\mu_{2}, \sigma_{2}\right)$, where $q$ is a coefficient between 0 and 1 , was compared with that of a single normal distribution $\mathcal{N}(\mu, \sigma)$ with mean $\mu$ and standard deviation $\sigma$. Taking the difference between the number of estimated parameters into account, the bimodal distribution fitted significantly better than the uni-modal distribution (log-likelihood ratio test, $\chi^{2}=1364, \mathrm{df}=3$, $P<0.0001$; Sokal and Rohlf 1995). We assumed that the first normal distribution $(\mu=0.13, \sigma=2.4$; backtransformed values) was related to intra-patch movements, whereas the second normal distribution $(\mu=5.5$, $\sigma=3.2$ ) was related to inter-patch movements. The large overlap between these distributions confirms that we cannot simply use step length to distinguish between intra- and inter-patch movements. The frequency
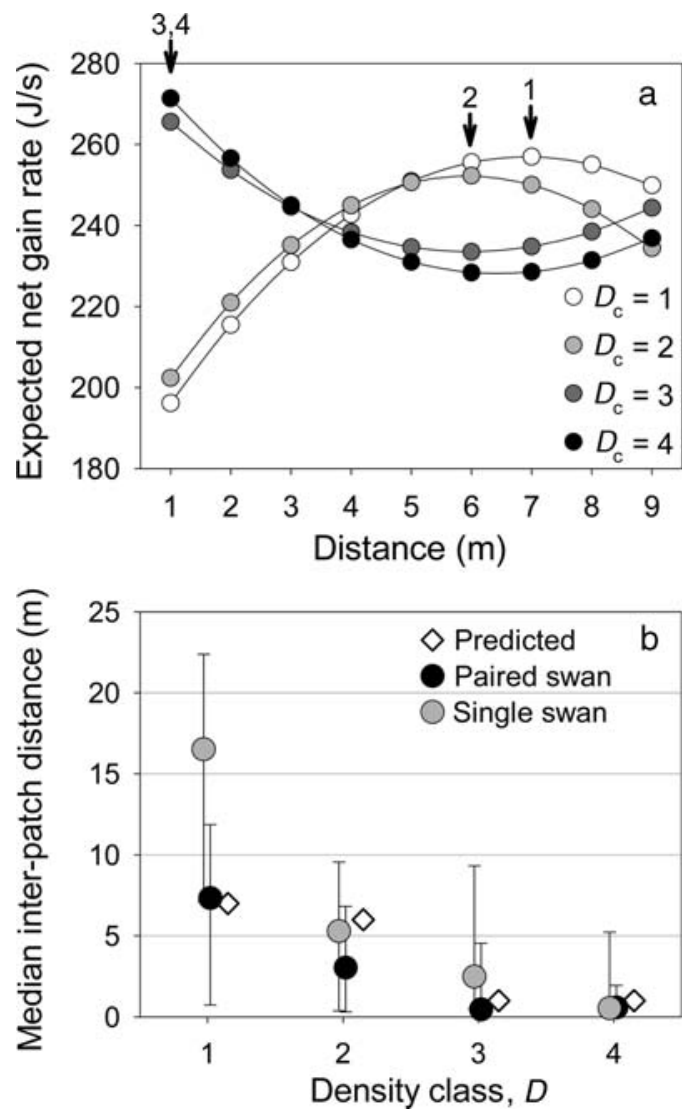

FIG. 2. (a) The net gain rate a Tundra Swan should expect in a patch at different distances from the current patch, given that the current patch is of a certain density class $\left(D_{\mathrm{c}}\right)$. Arrows indicate the distance where the highest gain rate is found. (b) Median length of inter-patch movements from patches with different food densities (classes 1-4, as in Fig. 1), separated for single and paired swans. Error bars denote confidence limits (25th-75th percentiles). Diamonds represent the inter-patch movements predicted for a swan that always moves to the patch where the highest gain rate is expected (see Model predictions: Length of inter-patch movements).

distribution of turning angles (Fig. 4b) was different for intra- and inter-patch movements. Within a patch, swans frequently conducted large turns (mean vector direction $=174^{\circ}$, mean vector length $=0.29$, angular deviation $=68^{\circ}$; cf. Cain 1989), i.e., they most frequently turned back in the direction they just came from. Between patches, however, they usually conducted small turns (average $=-2.5^{\circ}$, mean vector length $=0.21$, angular deviation $=72^{\circ}$ ), i.e., they moved forward.

\section{Observed responses to different tuber densities}

Removal of aboveground biomass during different stages of the growing season had a clear effect on the average tuber biomass in October $\left(F_{3,28}=24.2, P<\right.$ 0.001; Appendix B: Fig. B3). The lowest biomass density was observed in subplots that were "mowed" in June, whereas the highest density was observed in the control plots where biomass was not removed. Treatment had 


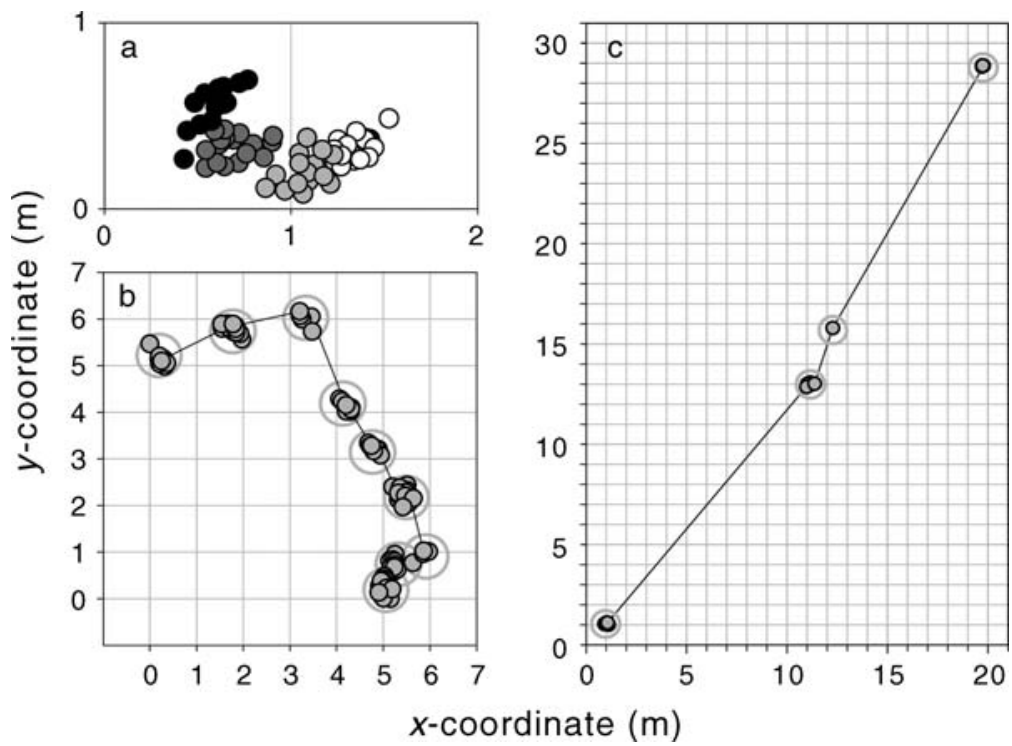

FIG. 3. Representative examples of small parts of the foraging path of Tundra Swans. The position of a swan was measured with a triangular fix every time it submerged its head. Squares measure $1 \times 1 \mathrm{~m}$. Lines connect subsequent measurements but do not necessarily correspond to the true path a swan traveled. (a) Typical path with very short inter-patch movements. Different gray circles indicate bouts belonging to different patches (first patch in white). (b) Typical path with intermediate inter-patch movement lengths. (c) Typical path with long inter-patch movements.

an effect on tuber number (AVOVA, $F_{3,28}=27.4, P<$ 0.001 ) and on average tuber size (ANOVA, $F_{3,28}=3.2, P$ $=0.039)$. Linear regression revealed that differences in the number of tubers in isolation already explained $86 \%$ of the observed variance in biomass density, whereas differences in tuber size only explained $39 \%$ of observed variance. Ninety-six percent of the variance in biomass density was explained in a multiple regression analysis in which both tuber number and tuber size were incorporated. Thus, much of the effect of the mowing on food availability was expressed as differences in tuber numbers.

Swans spent significantly more time in high- than in low-density patches $\left(F_{3,105}=4.4, P=0.006\right)$. This was manifested through a larger number of bouts $\left(F_{3,105}=\right.$ $3.1, P=0.03)$, rather than a longer bout duration $\left(F_{3,105}\right.$ $=1.6, P=0.19)$. More biomass was removed from highdensity patches than from low-density patches, i.e., consumption by swans was a function of initial biomass density (Fig. 5). Note that in this regression, the $y$ variable is not entirely independent of the $x$-variable. If biomass densities were measured with error, a spurious negative correlation would result. By simulation, we estimated that the results depicted here are significant (i.e., $P<0.05)$ as long as we assume that the relative measurement error is smaller than $52 \%$. The observed skew in foraging effort and the density dependency of biomass consumption indicates that swans assess the quality of patches and leave patches at some constant quitting harvest rate (Valone and Brown 1989). From the relationship between the biomass on offer and the biomass removed by the swans (Fig. 5), we can infer that the proportion of pondweed biomass within reach of the swans equals 0.733 , and that swans would deplete the pondweed bed to a biomass of $6.79 \mathrm{~g} / \mathrm{m}^{2}$ if all tuber biomass were within reach of the swans.

In accordance with our quantitative predictions, the length of an inter-patch movement was long $(>3 \mathrm{~m})$ if the food density in the former patch was low, whereas such movement was short $(<3 \mathrm{~m})$ if the food density in the former patch was high $\left(F_{3,105}=4.8, P=0.003\right.$; Fig. 2b). Movements of single swans were longer than movements of paired individuals $\left(F_{1,105}=6.0, P=\right.$ 0.016; Fig. 2b), and the quantitative agreement between predicted and observed lengths of movements was greater for paired than for single swans. The turning angle of inter-patch movements was not different for different tuber density classes $(W=6.612, P=0.358)$.

Swans encountered a relatively low food density if they moved a short distance from a low-density patch (class 1 and 2), and a higher density if they moved a longer distance (Appendix B: Fig. B4). For a movement from a high-density patch (class 3 ), the opposite was true: A swan encountered a patch with a relatively high density if the movement from that patch was short, and a relatively low density if this movement was long. No long movements were observed from a class 4 density patch (Appendix B: Fig. B4). The result of the observed movement policy was that food densities were encountered at a different frequency than on offer (Fig. 6), with the highest densities being visited most frequently. This is related to a higher long-term gain rate $G$ : Swans that move according to the observed policy achieved a $38 \%$ 

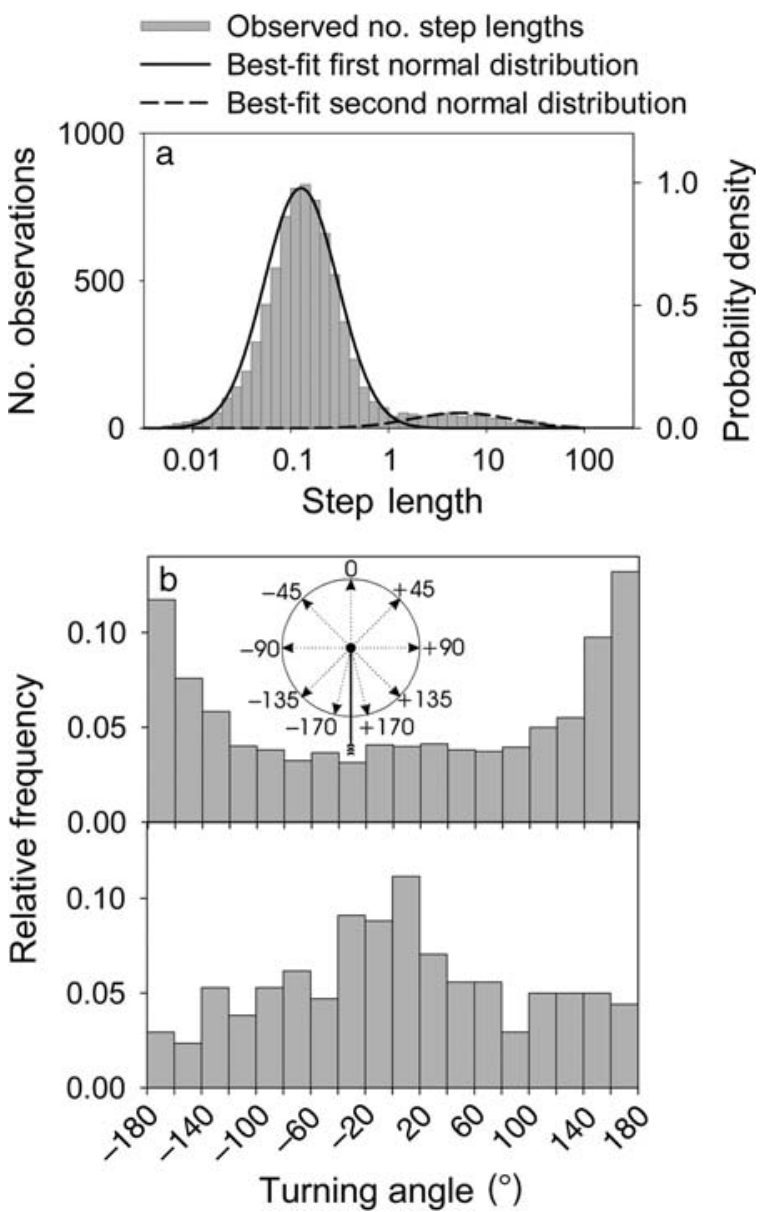

FIG. 4. (a) Frequency distribution of (log-transformed) movement lengths (step length, distance between two foraging bouts) of Tundra Swans foraging on Sago pondweed tubers (bars, left $y$-axis). This distribution is best described by a mixture of two overlapping normal distributions (lines, right $y$ axis; see Results: Foraging paths of Tundra Swans). (b) Frequency distributions of turning angles between subsequent movements, for intra-patch movements (upper panel) and interpatch movements (lower panel). A turning angle of $0^{\circ}$ corresponds to a forward movement, whereas an angle of $+180^{\circ}$ or $-180^{\circ}$ corresponds to a backward movement (see inset).

higher long-term gain rate than swans that encountered food densities at the frequency as on offer.

\section{DiscusSION}

\section{Adaptive responses to spatial heterogeneity in food abundance}

Tundra Swans seem to take advantage of heterogeneity in the abundance of pondweed tuber biomass in two different ways. Firstly, swans are sensitive to spatial variance and regulate the time in a patch in such a way that more time is spent in rich than in poor patches. The observation that more food is consumed from rich than from poor patches (Fig. 5) indicates that swans harvest patches down to a constant quitting harvest rate (Valone and Brown 1989). Pondweed tubers are expected to be cryptic to the swans. Consequently, swans cannot instantaneously recognize the quality of a patch, but rather assess the quality of a patch during foraging. The optimal patch use policy for such an assessing forager is to leave a patch as soon as the estimated (potential) encounter rate with prey drops to a certain critical encounter rate (see Green 1988, Olsson and Holmgren 1998). Olsson et al. (1999) and Van Gils et al. (2003) showed that foragers leave patches at a constant optimal estimated encounter rate. Whether Tundra Swans feeding on Sago pondweed use the aforementioned rule remains to be assessed.

Secondly, swans are also sensitive to the positive spatial autocorrelation in the abundance of pondweed biomass. Swans responded to this spatial pattern by making small movements from high-density and large movements from low-density patches (Fig. 2b). The length of inter-patch movements was in accordance with movement lengths predicted for swans that move to the patch where the highest net gain rate is expected (Fig. 2). The result of this strategic movement is that swans encounter high-density patches at a higher and lowdensity patches at a lower frequency than the frequencies these patches are on offer (Fig. 6), which results in a 1.4-times higher long-term gain rate. The result that a forager adjusts its movement to its recent foraging experience to enhance its long-term gain rate is not new (e.g., see c.f. Smith 1974 [thrushes foraging on earthworms], Zach and Falls 1976 [Ovenbirds foraging on mealworms], Pienkowski 1983 [plovers foraging on invertebrate prey], and Fortin 2003 [bison foraging on

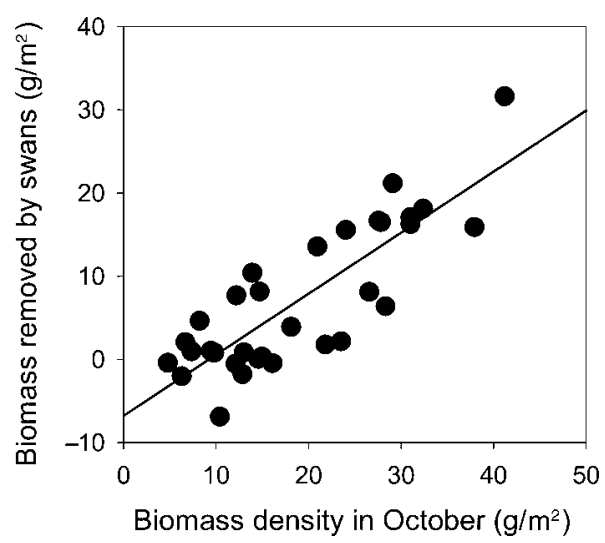

FIG. 5. The amount of Sago pondweed tuber biomass consumed by Tundra Swans from $10 \times 10 \mathrm{~m}$ subplots, as a function of the initial tuber biomass density in October. The line represents the least-square regression $(y=0.733 x-6.79, n=$ $\left.32, r^{2}=0.69, P<0.001\right)$. Consumption was calculated by subtracting biomass in October from biomass in November. Consequently, the $y$ variable is not completely independent from the $x$ variable (see Results: Observed responses to different tuber densities). 

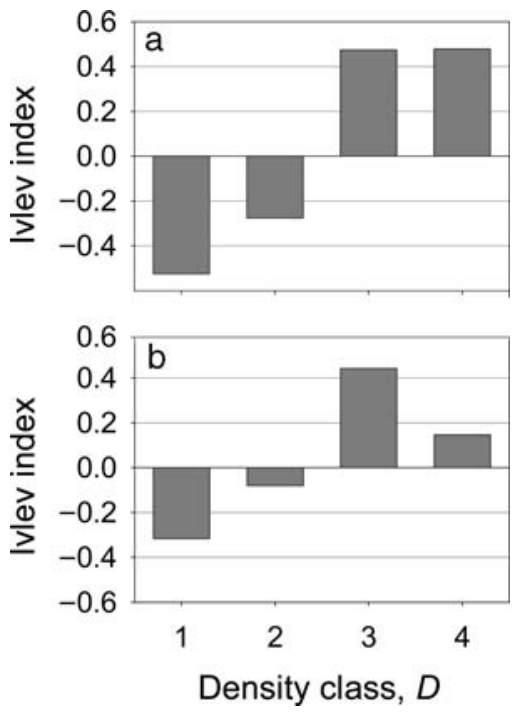

FIG. 6. Ivlev index, which compares the frequency in which a patch type is encountered with the frequency it is on offer, for different densities: (a) for paired swans and (b) for singletons. If this index is positive, the food density is encountered in a higher frequency than it is on offer. If this index is negative, the food density is encountered in a lower frequency than it is on offer.

vegetation]). However, in none of these examples was the distribution of food mapped in sufficient detail to be able to explain the length and/or direction of individual movements. The novelty of our study is that we used an economic approach and provided quantitative predictions that were tested in the field.

\section{Movement length and path sinuosity}

Movement between patches can be regulated by adjusting the length of movements, by adjusting the sinuosity of the path, or a combination of these. Swans only regulated the length of movements and not the sinuosity of the path. In contrast, thrushes only regulated sinuosity and not movement lengths (Smith 1974). In both examples, the effect of the nonrandom movement is that foraging effort is concentrated in profitable area. The question is whether the adjustment of movement length and the adjustment of path sinuosity are two sides of the same coin, i.e., are just different possible ways to achieve the same goal. There is no indication that thrushes cannot make smaller movements. One possible explanation for their constant move length might be that prey (earthworms in this example) perceive a nearby catch and respond to it by a retreat that decreases the probability that they are caught (Charnov et al. 1976, Stillman et al. 2000). Consequently, it makes no sense for a thrush to search the direct surroundings of the location where a prey was caught, although it remains beneficial to intensify search nearby. The food of the swans (pondweed tubers) is immobile, thus, foraging in a patch does not depress food availability in the adjacent area.
Why do swans not increase the sinuosity of their path after a rich patch was found, since this would further concentrate foraging effort in area that is rich in food (Benhamou 1992)? One explanation could be that a directional path avoids revisitation of a previously exploited area. A pondweed bed is an example of a continuous environment in which it might be very difficult to keep track of the position of exploited patches, since these are hidden under the water surface. The directionality of the movement path of the swans can also be an effect of the fact that swans forage in a flock that moves systematically through a pondweed bed. In this light, it would be interesting to see whether the movement of a swan depends on the position of conspecifics.

\section{Other factors that shape a foraging path}

The length of inter-patch movements was well predicted for movements from high-density patches, whereas a small discrepancy between the prediction and observation existed for movements from low-density patches. This discrepancy might be the result of a shortcoming in the calculation of the expected gain rates functions. Structure functions that are used in these calculations are derived from the data from the $10 \times 10$ grid, which limited our calculations on the expected gain rate to a maximum inter-patch distance of $9 \mathrm{~m}$, whereas the median inter-patch distance of a single swan after a visit to a low-density patch was $17 \mathrm{~m}$ (note that the maximum gain rate in our model was found at a distance $<9 \mathrm{~m}$ ). Furthermore, we do not know how representative our $10 \times 10$ grid is for spatial pattern in the whole study area and for parts of the study area with different sediment-water depth characteristics.

Alternatively, we can argue that the discrepancy between prediction and observation indicates that other factors might be important and influence the length of a movement, especially after encountering a low-density patch. For example, we should acknowledge that the pondweed bed has a limited size, and consequently, swans encounter borders that they avoid crossing by making shorter movements or by changing the direction of a movement. Secondly, the habitat is not homogeneous in sediment composition and water depth over larger spatial scales, which affects the net energy gain rates of swans (Nolet et al. 2001) and probably also the shape of the foraging path. Finally, in this study we focused on movements related to spatial pattern, and ignored that Tundra Swans are gregarious and that individuals frequently interact. We can imagine that social interaction can have subtle effects on the shape of the foraging path apart from the direct interactions that were excluded from the analyses. That effect could be very different for pairs and singles, with singles, as the subordinate social class in the flock (Badzinski 2003), presumably paying more attention to the positions of other swans when choosing a new foraging patch. Interestingly, solitary swans move twice as far as 
predicted. They seem to move not to the next rich patch, but to the one after that $(8.5 \mathrm{~m}+8.5 \mathrm{~m})$.

\section{Extrapolating to larger spatial scales}

Due to the laborious character of the tuber-sampling procedure, we could only study the distribution of tuber densities on a limited spatial scale. Nolet and Mooij (2002) investigated the distribution of tuber densities at a much larger spatial scale, though in less detail. Nolet and Mooij (2002) concluded that food resources occur in clumps with a diameter of roughly $10 \mathrm{~m}$, and hypothesized that swans responded to this large-scale pattern by moving in an intensive mode (low speed, sinuous paths) while within a clump and in an extensive mode (high speed, directed paths) while searching for a food clump.

These results fit with ours, where most of the swans we observed were probably foraging in a food clump and consequently in a low-speed intensive foraging mode. We can recognize different hierarchical levels at which spatial heterogeneity occurs (Kotliar and Wiens 1990). Viewed at a large scale, we recognize large food clumps (Nolet and Mooij 2002), where the size and location of a clump is probably related to habitat characteristics (sediment type, water depth). Within clumps, we observe small-scale heterogeneity in the distribution of food densities. The foraging path of swans is a reflection of this hierarchical structure: Swans move in an extensive mode between clumps and switch to an intensive mode if a clump is found. In the low-speed mode, swans adjust the length of an inter-patch movement to local food densities in order to profit from small-scale spatial patterns. We conclude that the shape of the foraging path of a Tundra Swan is a reflection of the spatial pattern in the distribution of tuber densities and can be understood within an optimal foraging framework.

\section{ACKNOWLedgments}

SBB Lauwersmeer is acknowledged for permission to work in their nature reserve. We thank all the people who assisted during tuber sampling and/or the swan observations, in particular, Oscar Langevoord, Jasja Dekker, Maja Roodbergen, Arjan van het Zelfde, Peter de Vries, Thijs de Boer, and Koos Swart. We thank Bart Driessen from GeoTrade BV for advice and support concerning the total station range finders and Wolf Mooij for statistical advice. We acknowledge Marcel Klaassen, Rudi Drent, Daniel Fortin, Ola Olsson, and two anonymous reviewers for inspiring suggestions and valuable comments on earlier manuscript versions. This is publication 3804 of the Netherlands Institute of Ecology (NIOO-KNAW) and publication 446 of the Centre for Wetland Ecology.

\section{Literature Cited}

Anderson, D. J. 1983. Optimal foraging and the traveling salesman. Theoretical Population Biology 24:145-159.

Badzinski, S. S. 2003. Dominance relations and agonistic behaviour of Tundra swans (Cygnus columbianus columbianus) during fall and spring migration. Canadian Journal of Zoology 81:727-733.

Batschelet, E. 1981. Circular statistics in biology. Academic Press, London, UK.
Beekman, J. H., M. R. Van Eerden, and S. Dirksen. 1991. Bewick's swans Cygnus columbianus bewickii utilising the changing resource of Potamogeton pectinatus during autumn in the Netherlands. Wildfowl Supplement 1:238-248.

Benhamou, S. 1992. Efficiency of area-concentrated searching behaviour in a continuous patchy environment. Journal of Theoretical Biology 159:67-81.

Bovet, P., and S. Benhamou. 1988. Spatial analysis of animals' movements using a correlated random walk model. Journal of Theoretical Biology 131:419-433.

Cain, M. L. 1989. The analysis of angular data in ecological field studies. Ecology 70:1540-1543.

Charnov, E. L. 1976. Optimal foraging, the marginal value theorem. Theoretical Population Biology 9:129-136.

Charnov, E. L., G. H. Orians, and K. Hyatt. 1976. Ecological implications of resource depression. American Naturalist 110:247-259.

Focardi, S., P. Marcellini, and P. Montanaro. 1996. Do ungulates exhibit a food density threshold? A field study of optimal foraging and movement patterns. Journal of Animal Ecology 65:606-620.

Fortin, D. 2003. Searching behavior and use of sampling information by free-ranging bison (Bos bison). Behavioral Ecology and Sociobiology 54:197-203.

Green, R. F. 1988. Optimal foraging for patchily distributed prey: random search. Technical report 88-2. Department of Mathematics and Statistics, University of Minnesota, Duluth, Minnesota, USA.

Holling, C. S. 1959. Some characteristics of simple types of predation and parasitism. Canadian Entomologist 91:385398.

Kacelnik, A., and C. Bernstein. 1988. Optimal foraging and arbitrary food distributions: patch models gain a lease of life. Trends in Ecology and Evolution 3:251-253.

Kareiva, P. M., and N. Shigesada. 1983. Analyzing insect movement as a correlated random walk. Oecologia 56:234 238.

Kotler, B. P., and J. S. Brown. 1990. Rates of seed harvest by two species of gerbilline rodents. Journal of Mammalogy 71: 591-596.

Kotliar, N. B., and J. A. Wiens. 1990. Multiple scales of patchiness and patch structure: a hierarchical framework for the study of heterogeneity. Oikos 59:253-260.

Krebs, C. J. 1989. Ecological methodology. Harper and Row, New York, New York, USA.

Legendre, P. 1993. Spatial autocorrelation: trouble or new paradigm. Ecology 74:1659-1673.

Li, H., and J. F. Reynolds. 1995. On definition and quantification of heterogeneity. Oikos 73:280-284.

Mangel, M., and F. R. Adler. 1994. Construction of multidimensional clustered patterns. Ecology 75:1289-1298.

Morales, J. M., D. T. Haydon, J. Frair, K. E. Holsinger, and J. M. Fryxell. 2004. Extracting more out of relocation data: building movement models as mixtures of random walks. Ecology 85:2436-2445.

Nolet, B. A., R. M. Bevan, M. Klaassen, O. Langevoord, and Y. Van der Heijden. 2002. Habitat switching by Bewick's swans: maximization of average long-term energy gain? Journal of Animal Ecology 71:979-993.

Nolet, B. A., O. Langevoord, R. M. Bevan, K. R. Engelaar, M. Klaassen, R. J. W. Mulder, and S. Van Dijk. 2001. Spatial variation in tuber depletion by swans explained by differences in net intake rates. Ecology 82:1655-1667.

Nolet, B. A., and W. M. Mooij. 2002. Search paths of swans foraging on spatially autocorrelated tubers. Journal of Animal Ecology 71:451-462.

Olsson, O., and N. M. A. Holmgren. 1998. The survival-ratemaximizing policy for Bayesian foragers: wait for good news. Behavioral Ecology 9:345-353.

Olsson, O., U. Wiktander, N. M. A. Holmgren, and S. G. Nilsson. 1999. Gaining ecological information about Baye- 
sian foragers through their behaviour. II. A field test with woodpeckers. Oikos 87:264-276.

Pienkowski, M. W. 1983. Changes in the foraging pattern of plovers in relation to environmental factors. Animal Behaviour 31:244-264.

Santamaría, L., and M. A. Rodríguez-Gironés. 2002. Hiding from swans: optimal burial depth of sago pondweed tubers foraged by Bewick's swans. Journal of Ecology 90:303-315.

Sawada, M. 1999. Rookcase: an Excel 97/2000 Visual Basic (VB) add-in for exploring global and local spatial autocorrelation. Bulletin of the Ecological Society of America 80:231234.

Smith, J. N. M. 1974. The food searching behaviour of two European thrushes. II. The adaptiveness of the search patterns. Behaviour 49:1-61.

Sokal, R. R., and F. J. Rohlf. 1995. Biometry. Third edition. W. H. Freeman, New York, New York, USA.

Sparrow, A. D. 1999. A heterogeneity of heterogeneities. Trends in Ecology and Evolution 14:422-423.

StatSoft. 2004. Statistica. Version 6.1. Statsoft, Tulsa, Oklahoma, USA.

Stephens, D. W., and J. R. Krebs. 1986. Foraging theory. Princeton University Press, Princeton, New Jersey, USA.

Stillman, R. A., J. D. Goss-Custard, and M. J. Alexander. 2000. Predator search pattern and the strength of interference through prey depression. Behavioral Ecology 11:597-605.
Turchin, P. 1998. Quantitative analyses of movement: measuring and modeling population redistribution in animals and plants. Sinauer Associates, Sunderland, Massachusetts, USA.

Valone, T. J. 1991. Bayesian and prescient assessment: foraging with pre-harvest information. Animal Behaviour 41:569-577.

Valone, T. J., and J. S. Brown. 1989. Measuring patch assessment abilities of desert granivores. Ecology 70:18001810.

Van Eerden, M. R., J. H. Beekman, M. Smit, and K. Oosterbeek. 1997. Patch use by Bewick's Swans Cygnus columbianus bewickii feeding on Sago Pondweed Potamogeton pectinatus in shallow lakes in the Netherlands: variation in exploitation threshold caused by social, environmental and time dependent factors. Pages 111-132 in M. R. Van Eerden, editor. Patchwork: patch use, habitat exploitation and carrying capacity for water birds in Dutch freshwater wetlands. Rijkswaterstaat, Directie Ijsselmeergebied, Lelystad, The Netherlands.

Van Gils, J. A., I. W. Schenk, O. Bos, and T. Piersma. 2003. Incompletely informed shorebirds that face a digestive constraint maximize net energy gain rate when exploiting patches. American Naturalist 161:777-793.

Walsh, P. D. 1996. Area-restricted search and the scale of dependence of patch quality discrimination. Journal of Theoretical Biology 183:351-361.

Zach, R., and J. B. Falls. 1976. Ovenbirds (Aves: Parulidae) hunting behavior in a patchy environment: an experimental study. Canadian Journal of Zoology 54:1863-1879.

\section{APPENDIX A}

A table showing parameter values used in the calculations on the expected net gain rate over distance (Ecological Archives E087137-A1).

\section{APPENDIX B}

Figures showing (1) an overview of the study area and study design; (2) Sago pondweed tuber biomass densities in the experimental grid; (3) mean Sago pondweed tuber density for plots in which aboveground biomass was removed during different stages of the growing season; and (4) the mean Sago pondweed tuber biomass density encountered by a swan when it made short and long movements from patches with different initial tuber density classes (Ecological Archives E087-137-A2). 